PUBLIC POLICY AND ECONOMIC GROWTH: DEVELOPING NEOCLASSICAL IMPLICATIONS

Robert G. King

Sergio Rebelo

Working Paper No. 3338

\author{
NATIONAL BUREAU OF ECONOMIC RESEARCH \\ 1050 Massachusetts Avenue \\ Cambridge, MA 02138 \\ April 1990
}

This paper is part of NBER's research program in Growth. Any opinions expressed are those of the authors and not those of the National Bureau of Economic Research. 
NBER Working Paper \#3338

April 1990

\section{PUBLIC POLICY AND ECONOMIC GROWTH: DEVELOPING NEOCLASSICAL IMPLICATIONS}

\section{ABSTRACT}

Why do the countries of the world display considerable disparity in long term growth rates? This paper examines the hypothesis that the answer lies in differences in national public policies which affect the incentives that individuals have to accumulate capital in both its physical and human forms. Our analysis shows that these incentive effects can induce large difference in long run growth rates. Since many of the key tax rates are difficult to measure, our procedure is an indirect one. We work within a calibrated, two sector endogenous growth model, which has its origins in the microeconomic literature on human capital formation. We show that national taxation can substantially affect long run growth rates. In particular, for small open economies with substantial capital mobility, national taxation can readily lead to "development traps" (in which countries stagnate or regress) or to "growth. miracles" (in which countries shift from ittle growth to rapid expansion). This influence of taxation on the rate of economic growth has important welfare implications: in basic endogenous growth models, the welfare cost of a 10 . increase in the rate of income tax can be 40 times larger than in the basic neoclassical model.

\author{
Robert G. King \\ Depariment of Economics \\ University of Rochester \\ Rochester, NY 14627 \\ and
}

Rochester Center for Economic Research
Sergio Rebelo

Kellogg Graduate School of Management Northwestern University

2001 Sheridan Rd

Evanston, IL 60201

and

Rochester Center for Economic Research 


\section{Introduction ${ }^{\circ}$}

Economists have long suspected that there is a link betreen national policies and long term rates of economic gronth. For example, Schultz [1981] suggests that many public policies contain disincentives for grogth because they reduce the regards to accumulation of a comprehensive concept of capital encompassing human as vell as physical capital. In this paper, ve shor that a basic Schultzian model has the property that modest variations in tax rates are associated vith large variations in long run gropth rates. Our model follors leads provided by Uzara [1965], Lucas [1988b], and Rebelo [1987]. In our analysis, changes in public policy can potentially explain periods of secular stagnation or high economic grogth. Public policy is particularly pogerful in affecting small open economies ith freely mobile capital. For these economies, taxes can easily shut dorn the grogth process, leading to "development traps" in ghich countries stagnate or even regress for lengthy periods :

The specific model that ve construct belongs to an important class of endogenous gronth models based on gork by Uzara [1965] and retains the folloving key properties on the basic neoclassical model of Soloz [1956], Sran [1963], Cass [1965], and Koopmans [1965]: (i) the existence of a constant asyptotic grosth rate; and (ii) competitive and optimal allocations coincide in the absence of public interventions. The crucial attribute of this class of models is that ther is a "core" of capital goods onich can be produced vithout the direct or indirect contribution of non-reproducible factors. 1

In developing our model re begin vith the analysis of individual decisions at given prices and then consider the implications of production structure. This path leads us to develop aspects of individual accumation 
technology not present in earlier studies that pere concerned vith aggregat behavior. He then examine the relation betzeen public policy and long term grovth, restricting the model's parameters to accord vith existing microeconomic and macroeconowic evidence, a methodology that has proven to provide a poverful organizing tool in other areas of research on aggregate beharior. ${ }^{2}$

Our analysis focuses exclusirely on taxation of comodity outputs. We have chosen to focus on taxation of this form since ve think that a variety of public interventions-including aspects of property rights enforcement and regulation-may be described in this manner, so that our conclusions can potentially be interpreted as bearing on other aspects of governmental activity.

Our investigation of the link betreen public policy and economic grovth is organized as follors. Section II provides a brief overvier of the basic neoclassical model and of a very simple endogenous grorth model. Both models are calibrated to accord vith long run evidence for the U.S. economy and then used to analyze the effects of taxation on real economic activity.

Section III develops our model of grozth through human capital accumlation and the incentive effects of public policy on this process. Our analysis proceeds in three stages. Folloring Rosen [1976] and Heckman [1976], discuss optimal individual accumulation of human capital and the influence of various taxes on optimal accumlation. To highlight the role of taxes and to conform to prior microeconomic studies, our analysis begins by taking the following key prices to be exogenous: the rage rate per unit of human capital; the price of investing in human capital; and the real interest rate on consumption loans. In the next tro stages of model development ve add the structure that makes these relative prices endogenous. First, ze 
study the production of consumption and investment goods, thile retaining an exogenous borroving and lending rate. This provides a framegork for discussing a small open economy's accumlation of nontraded human capital. In this section, the nature of the influence of tax policies on the price of investing in human capital is shown to depend on the nature of the technology for producing such investments. Second, ve describe a full general equilibrium in ghich the rate of return adjusts to equate borroring and lending or, equivalently, savings and investment. The influence of policy on the rate of return is a final factor affecting the gronth rate.

Section IV compares the zelfare effects of taxation in three economies: the basic neoclassical model, the simple endogenous groth model discussed in section II, and the grovth model that pe propose in section III. The main conclusion obtained from this comparison is that there are larger gelfare. costs of taxation in endogenous groyth models than in comparablo neoclassical models gith exogenous technical change. Fundamentally, this is because policy can influence the long run grovth rate in endogenous gropth models. A concluding section sumarizes our results and relates them to ongoing research on the theory of econonic grovth.

\section{Meoclassical Models of Economic Grodth: Old and Ie:}

When ge think about conomic grouth, most of us have in the back of our minds some variant of the basic neoclassical model of capital accumation due to Solov [1956], Sran [1963], Cass [1965], and Koopmans [1965]. In this paper ve construct and evaluat a neoclassical model that alters intertemporal technology in vays phich make sustainable grotth a feasible outcome then technology is time stationary. Before developing our specific model it is useful to briefly discuss stylized versions of old and neo 
neoclassical models of economic grozth. These tzo models have the same specification of preferences over consumtion $\left(C_{t}\right)$, so ve begin gith these: ${ }^{3}$

$$
U=\sum_{t=0}^{\infty} \beta^{t} \frac{1}{1-\sigma}\left(C_{t}^{1-\sigma}-1\right) \text { for } 0<\sigma<\infty .
$$

With this utility function constant grotth in consumption is optimal if the real interest rate is constant over time, ghich ge take as one of the "stylized facts" of economic development (see Raldor [1961] and Romer [1988a]). As in most of the gropth literature ve vill assume that per capita labor supply is inelastic at $\mathbb{N}$. To simplify the exposition ve abstract from population growth.

\section{II.1 The Basic Feoclassical Kodel}

In this economy there is a single good that is produced by combining physical capital $\left(\mathbb{K}_{t}\right)$ and labor according to a neoclassical production function $F(.)^{4}$ :

$$
Y_{t}=F\left(R_{t}, N X_{t}\right)
$$

Technological progress occurs at an exogenous rate and its effects on productivity are captured by the variable $x_{t}$ phich grovs at the "gross" rate $\gamma_{\mathbf{X}}, \boldsymbol{X}_{\mathrm{t}}=\gamma_{\mathbf{X}} \boldsymbol{X}_{\mathrm{t}-1}$. We assume that technical progress is labor-augmenting to ensure that steady-state grovth is feasible (see Svan [1963] and Phelps [1966]).

The resource constraint on consumption and investment $\left(I_{t}\right)$, and the difference equation that describes the accumulation of physical capital complete the specification of the technology.

$$
Y_{t}=C_{t}+I_{t}
$$




$$
K_{t+1}=I_{t}+(1-\delta) K_{t}
$$

As usual, $\delta$ denotes the rate of depreciation phich is assumed to be betreen zero and one.

In this economy there are tro modes of economic grorth. First, in the steady state, consumption, investment, output and capital all grop at rate $\gamma_{\mathbf{Z}}$. Second, from a lod initial level of the capital stock, the economy may exhibit gropth rates exceeding $\gamma_{\mathbf{X}}$, during a transition period in ohich the economy converges to its steady-state grodth path. In a companion paper (Ring and Rebelo [1989]) ve argue that the transitional dynamics of the neoclassical model cannot account for much sustained variation in rates of economic gropth-either across countries or time periods - without generating counterfactual imlications for factor prices or factor shares.

\section{Calibrating the Model}

To study the effects of taxation in the neoclassical model it is useful to calibrate it vith parameters that accord pith the U.S long term experience. Ve vill use the parameters of the baseline economy studied in our companion paper (King and Rebelo [1989]) ghich contains a detailed discussion of the model's calibration. Each time period is taken to represent a year and the discount factor $\beta$ is chosen so that the after-tax steady-state interest rate is $3.2 \%$. Momentary utility is taken to be logarithmic $(\sigma=1)$. The production function is assumed to be Cobb-Douglas, $F(K, H)=A^{1-\alpha} \mathbb{N}^{\alpha}$, He normalize $A=1$, phich is a choice of units for measuring output, and select a conventional value for labor's share $(\alpha=2 / 3)$. Finally, ge set the depreciation rate equal to $10 \%(\delta=10)$, the grodth rate of technical progress to $2 \%\left(\gamma_{X}=1.02\right)$, and the fraction of time devoted to rork to $20 \%(N=.20)$. 


\section{The Effects of Taxation}

Throughout the paper, the main tax experiment that ge consider is an unanticipated increase in the output/income tax rate-applied equally to all sectoral activities-from $20 \%$ to $30 \%$. Roughly, this difference represents a change from the average Japanese tar rate during 1965-1975 to the average U.S. tax rate over that period. (Atkinson and Stiglitz [1980, Figure 1-2], provide this measure of the arerage tax rate-tax revenues as a share of gross domestic product-for a number of countries). ${ }^{7}$

To isolate the effects of taration from those of government expenditures ge assume that the tax revenue is used to finance lum sum transfer payments. Within the basic neoclassical model, as is vell known, an increase in the income tax rate occasions a shift in the level of the steady-state path-but not in its slope-and sets in motion transitional dynamics. For our calibrated econony, the steady-state effects of an increase in the rate of income tax from $20 \%$ to $30 \%$ are a $18.2 \%$ drop in the capital stock and a $3.6 \%$ drop in consumption. The dynamics that characterize the transition betreen the tro steady states are depicted in Figure 1, there the dashed line represents the old steady-state path. The qualitative features of these dynamics are familiar: during the transition period the initial level of consumption rises in response to the tax increase so the economy "rorks off" the capital stock through lover net investment and temporarily high levels of consumption.

\section{II.2 L Simple Eeoclassical Hodel of Endogenous Grouth}

For organizing our thinking about economic grogth it is useful to consider the simplest endogenous grogth model. In this model all factors of 
production are reproducible and their quantity is sumarized by the composite capital good $R^{*}$. The production technology is given by

$$
Y_{t}=\mathbf{R}_{t}^{*}
$$

ghere $A>0$ is the time invariant productivity parameter. The resource and accumlation constraints are

and

$$
Y_{t}=C_{t}+I_{t}^{*}
$$

$$
R_{t+1}^{*}-R_{t}^{*}=I_{t}^{*}-\delta R_{t}^{*}
$$

It is easy to shor that the common grodth rate of consumption, investment, output and capital in this economy is:

$$
\gamma=[\beta R(\tau)]^{(1 / \sigma)}
$$

In this expression ge have defined $R(\tau)=[(1-\tau) A+1-\delta]$ as the gross private rate of return to the composite capital good. Thus, in an application of standard Fisherian principles, the grogth rate depends on the gap betpeen the rate of interest and the rate of time preference, rith the strength of this relation depending on the intertemporal elasticity of substitution $(1 / \sigma)$.

\section{Calibrating the Model}

We parameterize this economy to make it comparable to the basic neoclassical model just discussed. Ve choose $\sigma=1, \delta=.10$ and determine the values of $\beta$ and $A$ such that the economy groms at $2 \%$ a year and has an annual after-tax real interest rate of $3.2 \%$ vhen the rate of income tax is $20 \%$. 


\section{Effects of Taration}

As is clear from expression (II.5), an unanticipated increase in the tax rate $\tau$ produces an imediate shift in the level and slope of the growth path-there are no transitional dyamics. Higher tares pork to lower the rate of return, $R(\tau)$, and thus to lover the regard to accumlation. A rise in the tax rate thus lovers the long run gropth rate, which is a general characteristic of endogenous groth models stressed by Rebelo [1987]. The effects of increasing the rate of income tax from $20 \%$ to $30 \%$ on consumption and capital are represented in Figure 2. The economy's rate of grouth falls from $2 \%$ to $0.37 \%$ (in Table 4 this is reported as a decline of $1.63 \%$ in the growth rate). The reduction in investment associated with this slordown makes the initial level of consumption rise by $36 \%$.

We think that this model is a useful starting point for consideration of the effects of policy on long term grovth. Hovever, in a strict interpretation of $R^{*}$. it delivers endogenous long run grovth only by effectively ignoring labor input, which is the sole force inducing diminishing returns to capital in the basic technology of Solor [1956] and Svan [1963]. (Alternatively if $\mathbf{R}^{*}$ is viezed as a composite of physical and human capital then the assumption is that these are produced according to an identical technology.) In our analysis belor, we vill follor Lucas [1988b] in permitting labor input to be reproducible, i.e., permitting human capital accumulation. Then, ve can reintroduce the smooth substitution betreen factor inputs that ras a key motivation for Solor's [1956] specification of production technology. 


\section{Econowic Grovth through Bunan Capital Accurlation}

Our interest is in models of endogenous grorth that accord aith the major facts of economic derelopment. One stjlized fact is that national gropth rates do not display trends in the absence of major policy interventions. Another is that there is little evidence of long run trends in real interest rates. Folloring Solor [1970], re interpret these observations as evidence that steady-state models are a reasonable first approximation to reality, and ve focus on economies in phich the real interest rate is constant along steady-state paths. He therefore require that the production of both physical and human capital goods is goveraed by constant returns to scale technologies so that there are feasible steady-state grode paths be also continue to utilize the preferences described in (II.1) since these lead individuals to choose a constant growth of consumption when faced yith a constant interest rate.

The model economy that ve construct is thus of the class studied previously by Uzara [1965], Lucas [1988b] and Rebelo [1987] in that it highlights the societal allocation of resources betgeen current consumption and comprehensive accumlation (physical and human capital) under constant returns to scale. Hovever, our model is different in three respects from these earlier studies. First, in contrast to Uzana and Lucas, ve allor for a commodity input into the production of nev human capital, which seems emirically reasonable given our broad interpretation of this process. In this regard, De are also motivated by the analysis of Rebelo [1987], ohich indicated that the Uzara-Lucas specification restricts certain tax policies to have negligible effect on the steady-state grovth rate. Second; since ve vant to understand (i) the decentralization of accumulation decisions and (ii) gropth in an open economy ith traded physical capital and nontraded 
buman capital. Be require that the rate of buman capital investment be subject to diminishing point-in-time returns as in Rosen [1976]. Third, our model is designed to permit a quantitative evaluation of the effects of policy on economic gropth.

\section{1 The Core Elements}

To study the accumlation of physical and human capital, ve use a tro sector endogenous grozth model. As in the neoclassical model of the previous section, there is a single consumtion/physical investment good. This good is produced in sector 1 according to a constant returns-to-scale production technology with physical and human capital as its inputs. Hence, one technical constraint for the economy is

$$
C_{t}+I_{t}=Y_{1 t}=F_{1}\left(R_{1 t}, H_{1 t} H_{t}\right)
$$

As previously, $C_{t}$ and $I_{t}$ denote consumption and physical investment. Output of this commodity is $Y_{1 t}$ and physical capital and labor (human capital) inputs into this sector are denoted respectively by $K_{1 t}$ and $N_{1 t} H_{t}$.

The human capital investment good, which ve call $\mathrm{I}_{\mathrm{Ht}}$, is produced in the second sector vith another production technology that is constant returns to scale in the tro inputs, i.e.,

$$
I_{H t}=Y_{2 t}=F_{2}\left(X_{2 t}, H_{2 t} H_{t}\right) .
$$

The physical capital goods are taken to obey standard neoclassical accumulation equations, i.e.,

$$
\mathbf{K}_{j, t+1}-\mathbf{K}_{j, t}=I_{j t}-\delta_{K j} \mathbf{K}_{j t}
$$


- There $\delta_{\mathrm{KJ}}$ is the depreciation rate in sector $\mathrm{j}$. Aggregate physical capital investment is then the sum of the sectoral investments, i.e., $I_{t}=I_{1 t}+I_{2 t}$.

Our specification of the evolution of human capital embodies diminishing point-in-time capacity to grov, as in Rosen [1976],

$$
H_{t+1}-H_{t}=\theta\left(I_{H t} / H_{t}\right) H_{t}-\delta_{H} H_{t}
$$

vith $D \theta>0$ and $D^{2} \theta<0.10$ This specification of "adjustment costs" permits steady-state gropth if $\mathrm{I}_{\mathrm{H}}$ and $\mathrm{H}_{\mathrm{t}}$ grop at the same rate. Further, combined gith (III.2), our setup is consistent vith the vie that grogth in human capital combines labor and other inputs according to a production function as in Heckman [1976]. We assume that both physical and human capital investment are irreversible.

Finally, the sectoral allocations of labor must sum to the available stock, $\mathbf{H}$.

$$
N_{1 t}+N_{2 t} \leq N
$$

Since human capital is embodied in rorkers time, this allocation also determines the sectoral allocation of human capital.

With this specification of intertemoral technology, our model has a range of feasible balanced grovth equilibria in vhich consumption, physical investment, sectoral outputs, and capital stocks all gror at the same rate; this rate, ohich pe denote by $\gamma_{\mathrm{H}}$, is the human capital groth rate.

\section{Calibrating the Model}

Our objective is to explore the quantitative effects of tax policies on rates of economic grogth. For this purpose, ve need to specify aspects of the investment technologies (parameters of the $\theta$ function, $\delta_{H}, \delta_{R}$ ); 
production technologies (parameters of the functions $F_{1}$ and $F_{2}$ ): and tax structure. Our parameter selections are reported in Table 1.

Throughout our analgsis, re concentrate on the case where the production functions $F_{1}$ and $F_{2}$ are Cobb-Douglas, witb $F_{i}=A_{i} k_{i}{ }^{\left(1-\alpha_{i}\right)}\left(N_{i} H\right) \alpha_{i}$. We uniformly assume that the share of labor in sector $1\left(\alpha_{1}\right)$ is $2 / 3$, so that our results are compatible with those for the neoclassical model discussed above. Further, as in section II, ve normalize the constant term in the sector 1 production function to unity $\left(A_{1}=1\right)$ vhich, as earlier, represents a choice of units. In our quantitative analysis, ge assume that there is a uniform depreciation rate on physical capital in its tro uses, $\delta_{\mathrm{K} 1}=\delta_{\mathrm{K} 2}=\delta_{\mathrm{K}}=.10$.

The parameter choices for sector 1 are vell githin the range of selections studied in other settings, such as public finance, quantitative grovth theory, and business cycle analysis. Hovever, in specifying the human capital production process, there is less guidance from prior aggregative studies. We consequently start rith a benchmark vier that human capital production is not mech different from the production of output, so that $\alpha_{2}=$ $\alpha_{1}=2 / 3$ and $\delta_{\mathrm{H}}=\delta_{\mathrm{K}}=.10$. This set of parameter choices has the convenient implication that there are no transitional dynamics in response to tax changes if these are uniform across the sectors. Rather, both capital goods- $R$ and $\mathrm{E}-\mathrm{simply}$ grov forever at the ner steady-state rate, as in the simple model of section II. This implication is independent of the choice of the $e$ function; it holds generally if the tro sectoral production functions are the same.

There has been little research since that of Rosen [1976] on the estimation of the parameters of the $\theta$ function, ghich is a primary determinant of the rate of human capital accumulation. Ne employ a parameterization of the human capital accumulation technology rhich implies 
that: (i) buman capital declines at the depreciation rate if there is no investment expenditure $(\theta(0)=0)$; and (ii) there are locally no "adjustment costs" at zero gross investment so that $D \theta\left(I_{H} / H\right)=1$ at $I_{H t}=0$. The specific function $\nabla \theta$ use is

$$
\theta\left(I_{\mathrm{H}} / \mathrm{H}\right)=\left[\mathrm{I}_{\mathrm{H}} / \mathrm{H}+\theta^{\frac{1}{1-\theta}}\right]^{\theta}-\theta^{\frac{\theta}{1-\theta}}
$$

Our benchmark assumption is that the parameter $\theta$ takes on the value .5 .

To conduct quantitative experiments githin our general equilibrium model; it is also necessary to specify aspects of preferences- $\beta$ and $\sigma$-since these influence the equilibrium interest and grogth rates. Our procedure is as follogs de choose a value of the intertemporal elasticity of substitution in consumption $(1 / \sigma)$ and a baseline value for the after-tas interest rate $R(\tau)$ and grogth rate $\gamma_{H}$. Then, ge can compte tro "unknoms". in the model, the utility discount factor $\beta$ and the productivity parameter for sector 2 output, ${ }_{2}$. The former is pinned down by the Fisherian link betreen interest

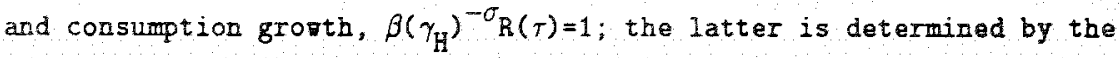
required grogth rate given efficient factor input proportions. Fixing these parameters, ge then explore hov steady-state interest rates and grovth rates vary as the tax structure is altered. 11 our benchmark preference case is to assume that the intertemporal elasticity of substitution is unity $(1 / \sigma=1)$. Finally, as in section II, ze use the after-tax steady-state real interest rate of $3.2 \%$ and grouth rate $2 \%$.

Sensitivity Anolysis: Given our uncertainty about the values of the human capital production technology, ge looked at the implications of alternative parameter values, suggested by prior theory or measurement, thich would act to reduce the gromth imlications relative to our benchmark. First, the Uzara [1965]-Lucas [1988b] specification is that only labor is used to 
produce the buman capital investment good $\left(\alpha_{2}=1\right)$. This parameterization has the very special property that taration of sector 1 output has no effect on the econory's steady-state grovth rate. Consequently, re study the implications of increasing our choice of $\alpha_{2}$ from our benchmark of .67 to a level of .95 . Second, in the applied labor economics literature, there is a variety of evidence on the magnitude of the depreciation of human capital: Hincer's [1974] estimate of $\sigma_{\mathrm{K}}=.012$ for individuals is the lorest one that ve found; Haley [1976] reports estimates in the range of 3 to $4 \%$. In our sensitivity analysis, pe reduce $\delta_{\mathrm{H}}$ to Mincer's value. Third, reasoning that increasing "adjustment costs" pould mitigate the sensitivity of gropth to economic policy, ve reduce $\theta$ to .25 . Fourth, we explored the implications of a value of $\sigma$ that implies a smaller degree of intertemoral substitution $(\sigma=5)$. Table 1 provides a sumary of the parameterizations that ve consider.

\section{Taxation of the Tro Sectors}

Throughout the analysis, ge consider taxation of sectoral outputs at rates $\tau_{j}$, ith the proceeds rebated lump sum. As in the basic neoclassical model of section II, gith constant returns-to-scale technologies this is equivalent to taxing the incomes from all factor services allocated to sector $j$ at the uniform rate $\tau_{j}$.

\section{2 Individual Human Capital Accmenlation}

We start by studying the individual's decision problem when the folloring prices are taken as given (i) the vage rate, (ii) the price of investing in human capital, and (iii) the interest rate. These are assumed constant over time, as they rill be in a steady state. The introduction of diminishing returns to point-in-time production is necessary for the individual's human 
capital investment demand to be vell defined. Othergise, vhen the rates of return to the accumulation of physical and human capital are identical (as they are in equilibrium) the individual allocations across these tro activities are indeterminate.

The individual maximization problem involves choosing sequences of consumption $\left\{\mathrm{C}_{t}\right\}_{\mathrm{O}}^{\mathrm{m}}$ and human capital investments $\left\{\mathrm{I}_{\mathrm{Ht}}\right\}_{0}^{\infty}$ so as to maximize lifetime utility (II.1), subject to an intertemporal budget constraint,

$$
\sum_{t=0}^{\infty}[R(\tau)]^{-t} C_{t} \leq B_{0}+\sum_{t=0}^{\infty}[R(\tau)]^{-t}\left[\nabla N H_{t}-p I_{H t}\right]
$$

vhere $R(\tau)$ is the market discount factor $(R=1+I(1-\tau)$, vith $I(1-\tau)$ being the after-tax real interest rate) and $B_{0}$ is the level of initial financial assets. The optimal human capital program is also constrained by the evolution equation for human capital, $\left[\mathrm{H}_{t+1}-\mathrm{H}_{t}\right] / \mathrm{H}_{\mathrm{t}}=\theta\left(\mathrm{I}_{\mathrm{Ht}} / \mathrm{H}_{\mathrm{t}}\right)-\delta_{\mathrm{H}}$

There is a separation of consumption from production decisions in this model, so that preferences do not influence the rate of human capital formation. Consumption grorth occurs at the familiar rate $\left(C_{t+1} / C_{t}\right)=[R(\tau) \beta]^{1 / \sigma}$

To examine the determination of the optimal grouth rate, it is convenient to rork vith the inverse of the adjustment technology, vhich states the inputs required to field a given flor of human capital outputs. Call this function $\Psi$, so that $I_{H t} / H_{t}=\Psi\left[\left(H_{t+1}-\left(1-\delta_{H}\right) H_{t}\right) / H_{t}\right]$. Substituting this expression into the lifetime budget constraint and maximizing vith respect to the human capital stocks, ge are led to the folloring efficiency condition:

$$
\nabla \mathbf{N}=\left(\mathrm{R}(\tau)-\gamma_{\mathrm{H}}\right) \mathrm{pD} \Psi\left[\gamma_{\mathrm{H}}-1+\delta_{\mathrm{H}}\right]+\mathrm{p} \Psi\left[\gamma_{\mathrm{H}}-1+\delta_{\mathrm{H}}\right]
$$


Imlicitly, this efficiency condition determines a function for the optimal gropth rate of human capital in the presence of "adjustment costs,"

$$
\gamma_{\mathrm{H}}=\gamma\left[\mathrm{z} / \mathrm{P}, \mathrm{R}(\tau), \delta_{\mathrm{H}}\right]
$$

The growth rate depends positively on the vage rate and negatively on the price of investing in human capital p.12 Since investment in human capital-like other investments-depends negatively on the interest rate $R(\tau)$ and on the depreciation rate of the capital good $\delta_{\mathrm{H}}$, the grovth rate also depends negatively on these factors. In addition, it depends implicitly on the parameters of the $\theta$ function as in other models gith adjustment costs to investment.

This formlation provides a convenient basis for discussing some theoretical results from the labor economics literature - pich generally viegs the investment process for human capital as untaxed-and to previev some of our results in the general equilibrium models studied belor. If ve subject labor income to a tax at rate $\tau_{\nabla}$, then the after-tax gage falls to (1- $\tau_{p}$ ) so that one gould expect a slondorn in buman capital grorth from this channel. (These imlications for human capital accumlation translate directly into implications for the groth of individual income, $\mathbf{w N H}_{t}$ ). However, there may be a countervailing effect from the influence of taxation on the cost of investing in human capital. If labor is the only input into buman capital investment and there is no direct taxation of the human capital activity, as in Rosen [1976], then $p$ is simply proportional to $\left(1-\gamma_{v}\right) \nabla$, so that there is a full offset on the relative price $\nabla / p$ and, thus, no effect on the grooth rate. In the alternative specification studied by Heckman [1976], labor is only one of the factors elployed in producing neg human capital, so that there is a smaller countervailing move in $\mathrm{p}$ from $\tau_{\nabla}$ and, thus, there 
continues to be a reduction in the grodth rate induced by the tax increase even if the human capital investment sector is not taxed.

\section{3 Prices Facing 1 Sall Open Economy}

For the purpose of studying a small open economy, ve need to explore the implications of the production structure for the prices and p. Thus in this section ve proceed part pay to a full dynamic general equilibrium, but we retain the assumption that the interest rate is exogenous, He make the conventional assumptions that there is international borroving and lending; trade in capital and consumption goods; and international immobility of labor/human capital. We also assume that all countries follog the "घorldride tax system" according to rbich agents pay taxes in their bome country on capital income from foreign investments but receive a tax credit for any taxes paid abroad on this income. ${ }^{13}$

\section{The Price of Investment in Human Capital}

For a small economy facing a given porld interest rate, the cost of producing a marginal unit of the human capital investment good is independent of the level of investment, since both of the production functions are constant returns to scale. In discussing the implication of analogous results for specialization in the production of traded goods in a vorld economy, Barter [1988] notes that they fundamentally derive from the "nonsubstitution theorem" of Samelson [1961] and Mirrlees [1969]. In our setting, since human capital is not traded, a small open economy vill not specialize if it grovs, i.e., it vill generally produce both final product and human capital investment. But it still faces a price of investing in human capital that is determined solely by domestic technology and taxes 
along with the forld interest rate; this price is not influenced by the domestic economy's choico betreen production of final output and human capital investment.

Folloging Baxter's [1988] Iine of argument, the capital intensity in sector 1 is pinned donn by the cost of capital under international capital mobility, $\mathrm{K}_{1 \mathrm{t}} /\left(\mathrm{N}_{1 \mathrm{t}} \mathrm{H}_{\mathrm{t}}\right)=\kappa_{1}\left[\left(\mathrm{R}(\tau)-1+\delta_{\mathrm{K} 1}\right) /\left(1-\tau_{1}\right)\right]$. Hence, the real wage rate is also determined by these variables, as $z=\left(1-\tau_{1}\right) D_{2} F_{1}\left(\kappa_{1}, 1\right)$. Finally, vith all of the input costs determined, the price of the investment good is given by

$$
\mathrm{P}=\left\{\left(\mathrm{R}(\tau)-1+\delta_{\mathrm{K} 2}\right) v_{\mathrm{R}}+\nabla v_{\mathrm{N}}\right\} /\left(1-\tau_{2}\right)
$$

where the "unit factor demands" $v_{K}$ and $v_{N}$ are functions of the relative factor price for sector $2, v /\left[R(\tau)-1+\delta_{K 2}\right]$.

\section{Implications of Taxation}

With these solutions in hand, ge can return to the effects of the analysis of taxation of sector 1 output-i.e., of a rise in $\tau_{1}$-discussed at the end of the previous section. First, if there is only labor in the sector 2 production function $\left(\alpha_{2}=1\right)$, so that $v_{R}=0$, then $p=\nabla /\left(1-\tau_{2}\right)$ and $\nabla / p=$ $\left(1-\tau_{2}\right)$. Hence, in our Cobb-Douglas setup, $\alpha_{2}=1$ ill be associated vith no effect of sector 1 taxation on economic gropth. Hovever, sector 2 taxation gill have a negative influence on grorth.

As stressed by Heckman [1976], vith $v_{H}<1$, a sector 1 tax increase gill reduce $\nabla / p$ and, hence, reduce the grotth rate of buman capital. (The same logic also implies that this relative price change vill generally occur vhen other produced inputs are used in the creation of neg human capital; it can even occur if these are flov inputs rather than capital $\left(\delta_{R 2}=1\right)$.) To some 
ertent, there vill also be factor substitution induced by an increase in $\tau_{1}$; that is, the input ratio $\kappa_{1}$ vill rise and an increase in the marginal product of labor vill occur. This factor substitution effect on the marginal product of labor vill partly mitigate the direct effect of taxation.

These general equilibrium adjustments are complex and, for this reason, ve resort to sirulations of parametric economies in studying the effects of taxation in small open economies. To maintain the link to individual consumer choico, ve also discuss the adjustment in the prices and $p$ so that one can see hor the equilibrium outcomes are decentralized.

Table 2 reports the results of some basic erperiments ith our small open economy setup, which holds fixed the rate of return $R(\tau)$. Prior to the fiscal change, ve assume that the economy has a grosth rate of $2 \%$ and the initial configuration of tax rates is $\tau_{1}=\tau_{2}=.20$. Further, ge assume that the economy does not trade with the rest of the porld at these tax rates. We then explore the implications of increasing $\tau_{1}$ to .3 and of increasing both $\tau_{1}$ and $\tau_{2}$ to 3

In our benchmark case, vo as sume the parameter values discussed in section III.1 above govera the econowy. Ho also consider tro other sets of parameter values. The first is a "high $\alpha_{2}$ " case vith $\alpha_{2}=.95$, thich is designed to illustrate the effects discussed earlier in this section. The second is to bring in greater investment adjustment costs; ve consider $\theta=25$.

In the benchmary case vith $\alpha_{1}=\alpha_{2}=2 / 3$, the $10 \%$ sector 1 tax increase-from $\tau_{1}=20$ to $\tau_{1}=30$ - lovers the grooth rate by over eight percentage points. (Even a one percent increase in the sector 1 tax rato loners grozth by tro percentage points). This slogdom is induced by a decline in $\mathbf{w} / \mathrm{p}$, the gross return to human capital investment from 14.92 to 13.97 percent per year. 
Taxing sector 2 at the same bigher rate $\left(\tau_{1}=\tau_{2}=.30\right)$ leads to a comlete shutdom of human capital investment $\left(\gamma_{\mathrm{H}}=\left(1-\delta_{\mathrm{H}}\right)\right)$.

ith a higher labor share, $\alpha_{2}=.95$, the effects of taxation of sector 1 are reduced, but still important: the increase from $\tau_{1}=.20$ to $\tau_{1}=.30$ reduces the growth rate by $2.84 \%$, so that-starting from a $2 \%$ gromth rate-the economy nould display negative gronth. As discussed previously, with lover capital input, the relative price $\nabla / p$ is less sensitive to taxation in sector 1. Taxing both sectors at the same higher rate $\left(\tau_{1}=\tau_{2}=.30\right)$ continues to lead to a complete shutdonn of the gropth process.

With more sharply increasing costs of gropth ( $\theta$ smaller), there is a smaller magaitude impact: growth falls by five percent phen the tax change is concentrated on sector 1 alone; previously, in the benchmark model, it fell by over eight percent.

\section{The Closed Economy General Equilibrium}

In the closed econony general equilibrium, the rate of return exerts a stabilizing influence relative to the prior analysis. In particular, the increases in the tax rate that lead to lover groptb bring about a decline in the real rate of return, ghich raises the amount of human capital investment undertaken at a given relative price $\nabla / p$. Therefore, the effects that we report in this section are necessarily smaller than those in the prior section. ${ }^{14}$

Results on the effects of taration on the grotth rate are provided in Table 3: in the benchrark economy, the basic tax experiment of raising the sector 1 tax rate from $\tau_{1}=.20$ to $\tau_{1}=.30$ leads to a one half percent decrease in the gropth rate; raising both tar rates by ten percent leads to a cut in the grotth rate of $1.5 \%$. This number is broadly in line with the grovth 
effects that ve found in the simle endogenous grovth model of section 2 (ohich imlied a grorth rate decline of $1.6 \%$ ), but it is slightly attenuated due to the presence of "investment adjustment costs" to human capital formation in the current setup.

The balance of the table reports a battery of sensitivity experiments abstracting from the transitional dynamics induced by the tax increase and focusing on steady-state effects. First, then ve consider the higher labor's share value, $\alpha_{2}=95$, ve find that the effects of taxing only sector 1 is sharply limited: instead of a .5\% cut in the grovth rate there is a .1\% reduction. This sensitivity analysis suggests that it is important to obtain good estimates of the relative imortance of taxed factors and untaxed factors in the human capital production process. Second, then re consider the Mincer [1974] value of depreciation $\delta_{\mathrm{H}}=.012$, the effects of a general tax increase are attenuated, falling from $1.5 \%$ to $.67 \%$. At the aggregate level, the depreciation rate on human capital involves the training of nev population members; the retraining of agents reallocated across jobs; and the continuing development of population members staying on the same job. Our sensitivity analysis indicates that it rould be valuable to obtain better measurements of the depreciation of human capital associated gith these activities. Third, there is a major influence of the intertemoral elasticity of substitution $(1 / \sigma)$ on the rate of economic grorth. Dur value of $\sigma=5$ is only about half found by Hall [1988], but it is nevertheless sufficient to substantially mitigate the effect of taxation on economic gropth. Fourth, ve experimented vith values of the investment technology parameter, reducing it to $\theta=.25$. As in the small open economy, the gropth rata declines relative to the benchmark 
experiment, but this influence is smaller than that of the otber sensitivity experiments.

From this battery of results, we conclude that taxation may affect the growtb rate in a quantitatively important zay, but that the magnitude of this influence depends, not surprisingly, on the production and tax structure.

\section{Melfare Inplications of Taration}

In the models of sections II and III ve eramined the effects on real activity of an increase in the income tax rate from $20 \%$ to $30 \%$. In this section we evaluate the predictions of our models for the velfare cost of this tax increase. Our objective is to illustrate the general principle that there are larger nelfare effects in endogenous grouth models than in the basic neoclassical model. As in the previous sections ve assume that the tax proceeds are rebated in a lump-sum fashion in order to isolate the substitution effects of taxation.

\section{Method of policy analysis}

The method that ze emloy is based on Lucas [1988a] and zorks as follogs. ${ }^{15}$ Denote by $\left\{C_{t}\right\}_{t=0}^{\infty}$ the consumption path associated vith the steady state of an economy with a $20 \%$ tax rate, and let $\left\{C_{t}^{\prime}\right\}_{t=0}^{\infty}$ denote the path that results after an unanticipated increase in the tax rate from $20 \%$ to $30 \%$. The gelfare loss associated gith this tax increase is the number $\phi$ such that

$$
U\left(\left\{C_{t}(1-\phi)\right\}_{t=0}^{\infty}\right)=v\left(\left\{C_{t}^{\prime}\right\}_{t=0}^{\infty}\right)
$$

Since $C_{t}$ grovs at a constant rate, $\phi$ is determined so that consumers are indifferent betreen (i) an increase in the tax rate to $30 \%$ and (ii) a 
situation in rhich the tax rate remains at $20 \%$ but their consumption level is reduced by $100 \times \phi \%$ in every period.

\section{1 The Basic Heoclassical Kodel}

In response to an increase in the income tar rate from $20 \%$ to $30 \%$, our parameterized version of the neoclassical model predicts that steady-state capital falls by $18.2 \%$ and consumption declines by $3.6 \%$ As Judd [1987] and Jorgenson and Yun [1988] have stressed, it is inappropriate to evaluate tax policies solely on the basis of these long run effects. In fact the velfare cost of taxation $\phi$ vould be independent of preferences in the neoclassical grovth model if only steady-state comarisons aere utilized. Hozever, the decline in steady-state consumption gives us an upper bound to the gelfare cost associated vith the tax increase. Since consumption is higher along the transition path than it is in the neg steady state, the zelfare cost is lover than the cost associated vith an immediate, permanent $3.6 \%$ drop in consumption.

The first line of Table 4 shows that, taking into account the entire transition path, the gelfare cost of raising the income tax rate from $20 \%$ to $30 \%$ in the benchmark model is $1.6 \%$. That is, the tax rate increase is equivalent (in utility terms) to an imediate $1.6 \%$ domaard shift in the steady-state consumption path.

We studied the sensitivity of this velfare cost to intertemporal elasticities of substitution different from the benchmark value of one. When the intertemporal elasticity of substitution in consumption is increased (i.e. $\sigma$ is reduced), the initial jump in consumption illustrated in Figure 1 is magnified and the velfare cost increased. For example, when $\sigma=1 / 2$, the velfare cost is $1.71 \%$. Symetrically, when $\sigma$ is increased, the velfare cost 
falls: phen $\sigma=2$, the velfare cost is $1.46 \%$. The intuition behind these results is familiar from discussions of the welfare cost of taxation in partial equilibrium (e.g., Husgrave and Musgrave [1980], page 310)): increasing the pillingness of agents to substitute across goods increases their response to the tax distortion and leads to a higher excess burden of taxation.

\section{2 The Simple Endogenous Grorth Model}

In the simple endogenous gropth model of section II there are no transitional dynamics. A permanent change in the tax rate implies an imediate shift in the level of the consumption path and a permanent change in the rate of grouth of consumption. For our benchmark case of unitary elasticity of substitution, increasing $\tau$ from $20 \%$ to $30 \%$ results in a $1.63 \%$ reduction in the grovth rate. As sketched in Figure 2, the reduction in rates of grovth induced by taxation is accompanied by an increase in the initial level of consumption. This effect on consunption is typically large-rith $\sigma=1$ there is a $36.2 \%$ increase in initial consumption. Yet, vith lover gropth due to taxation, gelfare unambiguously declines in this economy. Table 4 shors that this economy predicts dramatically higher values for the selfare cost of taxation than the neoclassical model. Fundamentally, this difference reflects the fact that the long run grovth rate is affected in the linear technology economy but not in the neoclassical model.

Hozever, one aspect of our calibration procedure contributed to the extraordinarily high velfare cost predicted by the model. By requiring that the discount rate $\beta$ be such that the economy chooses to grov at $2 \%$ rhen the income tax rate is $20 \%$ ve endoved this artificial economy vith extremely patient agents (the value of $\beta$ ge adopted pas .9884). The life-time utility 
of these agents vas severely affected ghen the tax rate increase reduced the returns to private accumilation of capital and hence the rate of gropth.

If ve calibrate the model by requiring that vithout taxes $(\tau=0)$ the economy grons at $2 \%$, the velfare effect is $16.3 \%$, which is much loper than the number ve reported in Table 4 but still significantly greater than the 1.6\% gelfare cost for the neoclassical model. In this case the $\beta$ adopted is .9576 which coincides with the discount factor used in our benchmark parameterization of the neoclassical model.

As in the neoclassical model, the relfare cost of taxation depends on the extent of intertemporal substitution in consumption. When $\sigma=2$, for example, the effect on the grouth rate is . $82 \%$ and the relfare cost is $63 \%$. When $\sigma=1 / 2$, the effect on the gronth rate is $3.2 \%$ and the relfare cost is $72 \%$

\section{3 The Tro-Sector Endogenoug Growth HodeI}

When ve consider tax increases that are uniformy levied on both sectors 1 and 2 , the tro-sector endogenous grodth model has positive imlications that are broadly the same as the simple model of endogenous economic grorth. Only the existence of "adjustment costs" alters these implications, yielding slightly smaller gropth effects.

In terms of pelfare ffects of uniform sectoral taxation, the final line of entries in Table 4 makes clear that the pelfaro effects are also very close to those ve found for the simple model. The cost of a $10 \%$ increase in taxation is around $60 \%$ of consumption. As in the simple endogenous grorth model, the gronth and velfare effects are increased (decreased) if individuals are more (less) gilling to substitute over time. For $\sigma=1 / 2$, 
the grovth rate falls by $2.97 \%$ and the welfare cost measure is $76 \%$. For $\sigma=$ 2 , the growth rate falls by $.77 \%$ and the relfare cost is $58 \%$.

Other tax experiments-such as taxing only sector 1 or considering different labor share in the tro sectors-generally imply transitional dynamics which requires that explicitly solve for complete equilibrium paths as in the basic neoclassical model. We plan to pursue these experiments in our future research.

\section{Conclusions}

In this paper ge proposed a model of economic gromth in which a comprehensive measure of "technical progress" is made endogenous along the lines suggested by Uzana [1965], Lucas [1988b] and Rebelo [1987]. By interpreting this compehensive measure as sociai investment in "buman capital," our analysis provides a potentially valuable formalization of the ideas of Schultz [1961, 1981] on economic development. Using this interpretation, ge build explicit microfoundations for a tro sector model of endogenous econonic growth. Wen we calibrate our model with parameter values that accord with the U.S. long run experience, we reach three major conclusions, as follors.

First, ve find that public policies can ezert a quantitatively iarge influence on the average growh rates of econowies operating in isolation. Policies can display these effects because they influence private incentives for accurnlation of physical and human capital as in Schultz [1981]. Further, these incentive effects of taration are reinforced in open economies that haye access to international capital markets. In both open and closed economies, relatively small changes is tax rates can lead countries to stagnate or even regress for lengthy periods, if these policies eliminate 
incentives for grovth. Our explanation of "no-grovth steady states" contrasts Jith that offered by Becker, Murphy and Tamura [1988] and Azariadis and Drazen [1988]. In those analyses, aspects of the technology give rise to miliple steady states so that economies vith different initial conditions may converge to steady states vith different rates of grorth even in the absence of cross-country heterogeneity in public policy.

Second, the effects of taxation depend importantly on aspects of the production technology for ned human capital, about vhich there is presently insufficient information. In part, this reflects the fact that our human capital good is a comosite of many different activities and that 7 have not taken a sufficiently precise stand on its essential content. On the other hand, there has been little research in labor economics since that of Rosen [1976] and Heckman [1976] on the parameters of individual technologies for investment in human capital. Our research indicates that macroeconomic policy analysis rould be aided by additional microeconomic measurement.

Third, since policies have the potential to influence the grovth rate in models rith endogenous long run grotth, there is generally a much larger quantitative influence of policies on velfare than in the neoclassical model where the gropth rate is governed by the exogenous rate of technical progress. Some experimenty comparing neoclassical and endogenous gropth models suggest that this difference can be quantitatively imortant.

In sumary, rith the results of the present paper, ve find ner promise for the hypotheses of Schultz [1981] that incentive effects of policy can influence economic activity-taxation can readily lead to development traps and grorth miracles. Models of endogenous economic gronth thus provide nev analytical paths for studying old problems in the economics of development. 


\section{References}

Atkinson, A. B. and I. E. Stiglitz. Lecture on Public Economics, Ner York:

McGraz Hill, 1980.

Azariadis, C., and A. Drazen. "Threshold Externalities in Economic

Development." Manuscript. University of Pennsylvania, May 1988.

Baxter, M. "Dynamic Real Trade Models." Manuscript. University of

Rochester, 1988.

Becker, G. Human Capital. Ne York: Columbia University Press, 1964.

Becker, G., T. Murphy, and R. Tamara. "Economic Grotth, Human Capital and

Population Groth." Paper prepared for the conference on "The Problem of Development" at the Institute for the Study of Free Enterprise, State University of Hed Yort, May 1988.

Braun, R. "The Dynamic Interaction of Distortionary Tares and Aggregate Variables in Postwar U.S. Data." Manuscript. Carnegie-Hellon University, 1989.

Break, G. F. "The Incidence and Economic Effects of Taxation." In The Economics of Public Finance, edited by A. Blinder et. al. Yashington DC: Brookings Institute.

Cass. D. "Optinum Grovth in an Aggregative Model of Capital Accumiation." Revier of Economic Studies 32 (July 1965): 233-240.

Ghez, G. and G. Becker. "A Theory of the Allocation of Time and coods over the Life Cycle." In The Allocation of Time and Goods Over the Life Crcle edited by G. Ghez and G. Becker. Hez York: Columbia Unizersity Press, 1975 .

Heckman, J. "A Life-Cycle Model of Earnings, Learning, and Consumtion." Journal of Political Economy 84 (August 1976): S11-S44. 
Haley, "Estimation of the Earnings Profile of Optimal Human Capital Accumlation." Econometrica 44 (Hovember 1976): 339-357.

Hall, R. "Intertemoral Substitution in Consumption." Journal of Political Economy 96 (April 1988): $339-357$.

Hamilton, I. "Taxation, Savings and Portfolio Choice in a Continuous Time Model." Public Finance IXXIII (1987): 264-282.

Jones, L. and R. Manuelli. "A Convex Model of Equilibrium Grorth." Forthcoming Journal of Political Economy.

Jorgenson, D. and X. Yun. "Tax Policy and the U.S. Economy." Manuscript. Prepared for the Conference on "The Problem of Economic Development," at the Institute for the Study of Free Enterprise, State University of Ner York, May 1988 .

Judd, K. "The Velfare Effects of Factor Taxation in a Perfect-Foresight Model." Journal of Political Economy 95 (August 1987): 675-709. Raldor, N. "Capital Accumulation and Economic Grorth." In the Theory of Capital, Lutz and Hagre editors. Nez York: St. Martin's Press, 1961. Ring, R. G. and C. I. Plosser and S. T. Rebelo. "Production, Grorth and Business Cycles, I. The Basic Heoclassical Model." Journal of Monetary Economics 21 (March/May 1988a) : 195-232.

Ring, R. G., C. I. Plosser and S. T. Rebelo, "Production, Gronth and Business Cycles, II Mar Directions." Journal of Monetary Economics 21 (March/May 1988b): 309-341.

Ring, R. G. and S. T. Rebelo. "Transitional Dynamics and Economic Grorth in Heoclassical Models." Manuscript. University of Rochester, 1989. 
Toopmans, T. "On the Concept of Optimal Grogth." In The Econometric

Approach to Development Planning. Chicago: Rand McHally, 1965.

Lucas, R. E., Jr. Hodels of Business Cycles. Mer York: Basil Blackell, $1988 \mathrm{a}$.

Lucas, R. E., Jr. "On the Hechanics of Economic Detelopment." Journal of Monetan Economicg 22 (July 1988b): $3-42$.

Lucas, R. E., Jr. "Hethods and Problems in Eusiness Cycle Theory." Journal of Monez. Credit and Banking 12 (November 1980): 696-715.

HeGratten, E. "The Macroeconomic Effects of Tax Policy in An Equilibrium Model." Manuscript. Duke Vniversity, 1989.

HCLure, C. "General Equilibrium Incidence Analysis: The Rarberger Model After Ten Years." Journal of Public Economica 4 (February 1975): $125-161$.

Mehra, R. and E. C. Prescott. "The Equity Premium: Auzzle." Journal of Monetarp Economics 15 (March 1985): 145-161.

Hincer, J. Schooling, Experience and Earnings. Ner York: Columbia University Press, 1974.

Mirrlees, J. "The Dynamic Monsubstitution Theorem." Revier of Economic Studies 36 (January 1969): 67-75.

Musgrave, R. A. and P. B. Musgrave. Public Finance in Theory and Practice, 3rd edition. Mer York: MeGrag Bill, 1980.

Rebelo, S. "Long Run Policy Analysis and Long Run Grotth." Manuscript. University of Rochester, 1987.

Romer, P. "Increasing Returns and Long Run Groth." Journal of Political Economy 94 (October 1986): 1002-1037. 
Romer, P. "Capital Accumalation in the Theory of Long Run Grorth." In Modern Business Cycle Theory edited by R.J. Barro. Her York: Wiley a Sons, 1988 .

Romer, P. "Endogenous Technological Change." Manuscript. Prepared for the conference on "The Problem of Development" at the Institute for the Study of Free Enterprise, State University of Hez York, $1988 \mathrm{~b}$.

Rosen, S. "A Theory of Life Earnings." Journal of Political Economy 84 (August 1976): S45-S67.

Samuelson, P. "A Hed Theorem on Honsubstitution." In Honey, Grovth, and Methodology, published in honor of Johan Akerman. Lund, Sreden: Social Science Studies Vol. 20, 1961.

Schultz, T. "Investment in Human Capital." American Economic Revier 51 (March 1961): 1-17.

Schultz, T. Investing in People: The Economics of Population Quality.

Berkeley: University of California Press, 1981.

Solor, R. M. "A Contribution to the Theory of Economic Grogth." Quarterly Journal of Economics 70 (February 1956): 65-94.

Solog, R. M. Gropth Theory: An Exposition. Hey York and Oxford: Oxford University Press, 1970 .

Sumers, R. and A. Heston. "Improved International Comparisons of Real Product and its Composition: 1950-1980." Revieg of Income and Health 30 (June 1984): 207-262.

Sran, T. "On Golden Ages and Production Functions." In Economic Development Eith Special References to Southeast Asia, edited by $K$. Berrill. London: Kacmillan, 1963.

Stenson, D. "The Impact of U.S. Tax Reform on Foreign Investment in the United States." Manuscript. MIT, 1989. 
Uzara, H. "Optimal Technical Change in an Aggregative Model of Economic Grotth." International Economic Revieg 6 (January 1966): 18-31. Wyane, . "The Effects of Government Purchases in a Perfect Foresight Model." Manuscript. University of Rochester, 1988. 


\section{Footnotes}

This paper is a substantially revised version of one prepared for the conference on "The Problem of Development" held at the State University of Her York at Buffalo in May 1988. The analysis of the tro sector model in our rork, particularly in its open economy versions, drazs heavily on some recent research by Marianne Baxter [1988]. He also thank her for pointing out the relationship betreen our model building activity and the arguments of $T . \mathrm{H}$. Schultz [1981]. Finally, ve have benefited from comments by Stanley Fischer and Arnold Harberger- $\rightarrow$ ho discussed the paper at the Buffalo conference-as pell as by Renneth Judd, sho discussed the paper at the Sumer Econometric Society meetings Support from the National Science Foundation is gratefully acknorledged.

'This class of models is very large, including structures vith many capital stocks in the grovth "core" and pith nonreproducible factors outside the grovth "core" (Rebolo [1987]); or oith steady states that are only asymptotically obtained (Jones and Manuelli [1990]).

${ }^{2}$ Lucas [1980] provides cogent arguments for combining aggregate and microeconomic evidence to restrict dynamic macroeconomic models of business fluctuations. Other applications of this strategy include Mehra and Prescott's [1985] vork on asset pricing and recent work on real business cycles, as surveyed by Ring, Plosser and Rebelo $[1988 a, b]$.

${ }^{3}$ As is conventional vith constant elasticity specifications, pe assume that $\sigma=1$ corresponds to logarithmic momentary utility.

${ }^{4}$ neoclassical production function is constant returns to scale, concave, trice continuously differentiable, satisfies the Inada conditions, and specifies that each production factor is essential in production. 
With a tzenty percent tar rate on final output, this number is consistent with the $6.5 \%$ figure used in Ring and Rebelo [1989]. Let the before-tax marginal product of capital be MPR and the after tax marginal product be (1- $)$ MPR. The rate of return to capital investment is then $(1-\tau)$ MPK $-\delta$. If ge take the before-tax rate of return, MPT $-\delta$, to be .065 , then using $\delta=.10$ and $T=.2$, ve arrive at an after-tax rate of return of $.8(.165)-.10=.032$.

The equivalence between output and input taxation under constant returns to scale is discussed by Break [1974] and McLure [1975]; ktkinson and Stiglitz [1980] provide a convenient sumary.

${ }^{7}$ The average tax rate is clearly a crude proxy for the income tax rate in our model but $\$ 0$ viev it as a natural starting point given that it is very hard to map the comlex tax systems that most countries adopt into stylized descriptions that can be used in calibration exercises such as ours. For general discussions of these difficulties and suggestions for improvements on our proxy see Braun [1989], McGratten [1989] and Hyne [1988].

${ }^{8}$ These tro requirements imly values of $A$ and $\beta$ as follors. First, the value of $\mathrm{A}$ is .1650 , since the before-tax interest rate is $6.5 \%$ and the depreciation rate is $10 \%$. The value of $\beta$ is then given by the equation $\beta R(\tau) \gamma^{-\sigma}=1$, where the after-tar interest rate, $\mathrm{R}(\tau)$, is $3.2 \%$.

${ }^{8}$ hn important assumption in our approach is that the changes in productivity sumarized by the evolution of the composite human capital good are embodied in the representative zorker. Ses Romer [1986, 1988b] for analyses that do not rely on this embodiment assumption.

${ }^{10} \mathrm{By} \mathrm{Dg}(x)$, ve mean the derivative of the function $g$ vith respect to $x$; correspondingly, $D^{2} g(x)$ denotes the second derivative.

${ }^{11}$ The details of this procedure are reported in Appendix A. 
${ }^{12}$ It also depends positively on the number of hours, $N$, which is exogenous in our model. In economies vith variable labor supply, therefore, policy may affect human capital accumulation via the supply of labor, a channel not considered here.

${ }^{13}$ The U.S., Japan and the U.K. follor this tax system. An alternative tax convention is the "territorial system" phich exempts from taxes all capital income earned abroad. See Spenson [1989] for a detailed discussion.

${ }^{14}$ To compute the closed economy general equilibrium, essentially, ve add the requirement that $\beta\left(\gamma_{\mathrm{H}}\right)^{-\sigma} \mathrm{R}=1$ to the preceding analysis. See appendix A.

${ }^{15}$ This method is closely related to that used by Hamilton in his [1987] study of the effects of taxation on risk taking. Our measure of the velfare effects of taxation rould not be appropriate if ve pere addressing normative questions such as the design of an optimal tax system, since ve do not impose that the tax revenue must be the same in the tro regimes compared. If this restriction vere imposed, our velfare measure vould coincide vith the compensating variation used by Hamilton [1987]. We thank Ken Judd for making us avare of Hamilton's vork. 


\section{TLBLE 1:}

Parameters Lor Tax Experiments

in Tro Soctor Endogezous Grorth Kodel

Hodel Componer:

Parameter Values Studied:

Sector 1: Consumtion/Phyical Integtment

$$
\text { (III.1) } F_{1}=A_{1} R_{1}^{\left(1-\alpha_{1}\right)}\left(\mathbb{R}_{1} \text { B) } \alpha_{1:}: \quad k_{1}=1 \quad \alpha_{1}=2 / 3\right.
$$

Sector 2: Human Capital Iavestoent

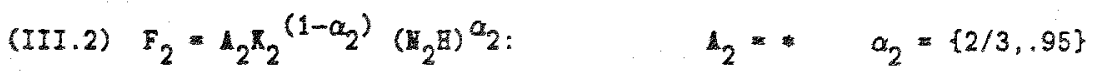

Evolution of Physical Capital stocis

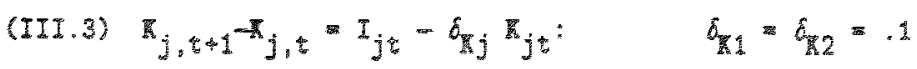

Evolution of guman Capital Stocks

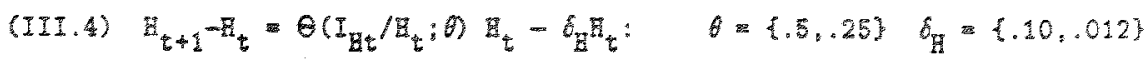

Prelerezen

$$
\mathrm{U}=\sum_{t=0}^{\infty} \beta^{t} \mathrm{u}\left(c_{t} ; \sigma\right): \quad \sigma=\{1,10\} \quad \beta=
$$

Injidal Mates

Lter-Tax Real Interast Rsto

$R(\tau)=1.032$

Real Grozth Rato

$\gamma_{\text {落 }}=1.02$

Sectoral Tax Rates

$\tau_{1}=.20 \quad \tau_{2}=.20$

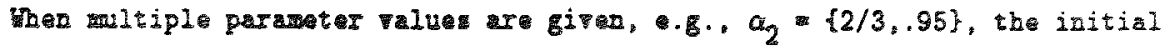

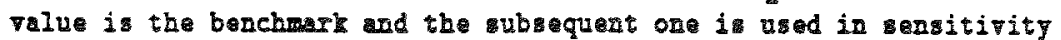

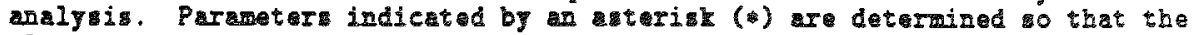
closed economy general quilibrium produco th injtial values of interest and grouth rates et initial tax rates.

The functions $u(c)$ and $\theta\left(I_{\mathrm{H}} / \mathrm{H}\right)$ are $\mathrm{givan}$ in text quations (II.1) and (III.6) respectively. The reierant parameter 10110 the principal argunent, $i .0$. $u(c ; \sigma)$ and $\theta\left(I_{\mathrm{H}} / \mathrm{g}_{\mathrm{a}} ; \theta\right)$. 


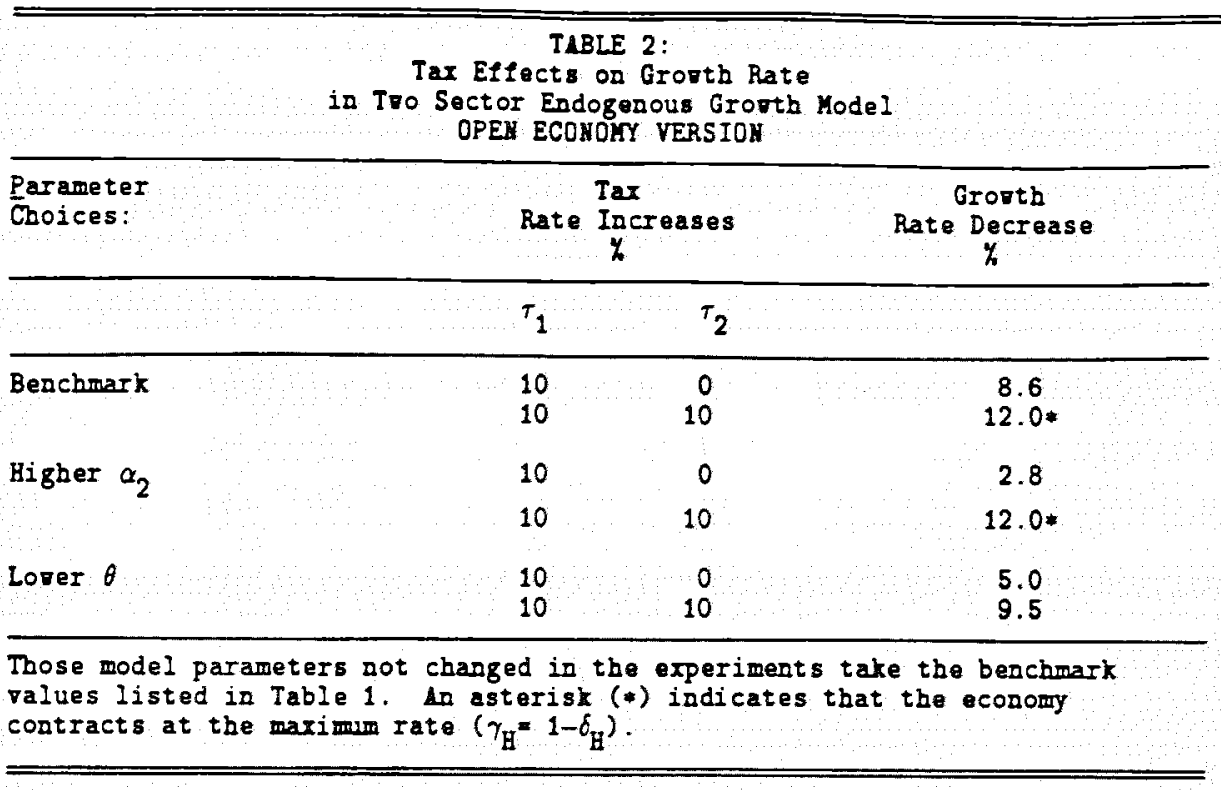


TABLE 3:

Tax Effects on Grorth Rat

in Tro Sector Endogenous Grogth Model

CLOSED ECOMOKY VERSIOH

\begin{tabular}{|c|c|c|c|}
\hline \multirow[t]{2}{*}{$\begin{array}{l}\text { Parameter } \\
\text { Choices: }\end{array}$} & \multicolumn{2}{|c|}{ Rate Increases } & \multirow[t]{2}{*}{$\begin{array}{c}\text { Grotth } \\
\text { Rate Decrease } \\
\%\end{array}$} \\
\hline & $T_{1}$ & $\tau_{2}$ & \\
\hline Benchmark & 10 & 10 & 1.52 \\
\hline Benchmark & 10 & 0 & .52 \\
\hline Higher $\alpha_{2}$ & 10 & 0 & .11 \\
\hline Righer $\sigma$ & 10 & 10 & .31 \\
\hline Lozet $\delta_{\mathrm{H}}$ & 10 & 10 & .67 \\
\hline Lozer $\theta$ & 10 & 10 & 1.38 \\
\hline
\end{tabular}

Benchmark and alternative parameters used in these experiments ore given in Table 1. 
TLBLE 4

Helfare Effects of Tar Incresse in Three Dypamic Models

\begin{tabular}{|c|c|c|c|}
\hline & $\begin{array}{l}\text { Initial } \\
\text { Consumption } \\
\text { Increase } \\
y\end{array}$ & $\begin{array}{c}\text { Grofth Rate } \\
\text { Decrease } \\
\%\end{array}$ & $\begin{array}{c}\text { Uelfare } \\
\text { Cost } \\
\%\end{array}$ \\
\hline Basic Neoclassical Model & 6.6 & 0 & 1.6 \\
\hline Simple Endogenous Grorth Model & 36.2 & 1.63 & 65.4 \\
\hline Tro-Sector Endogenous Grorth Model & 34.5 & 1.53 & 62.6 \\
\hline
\end{tabular}




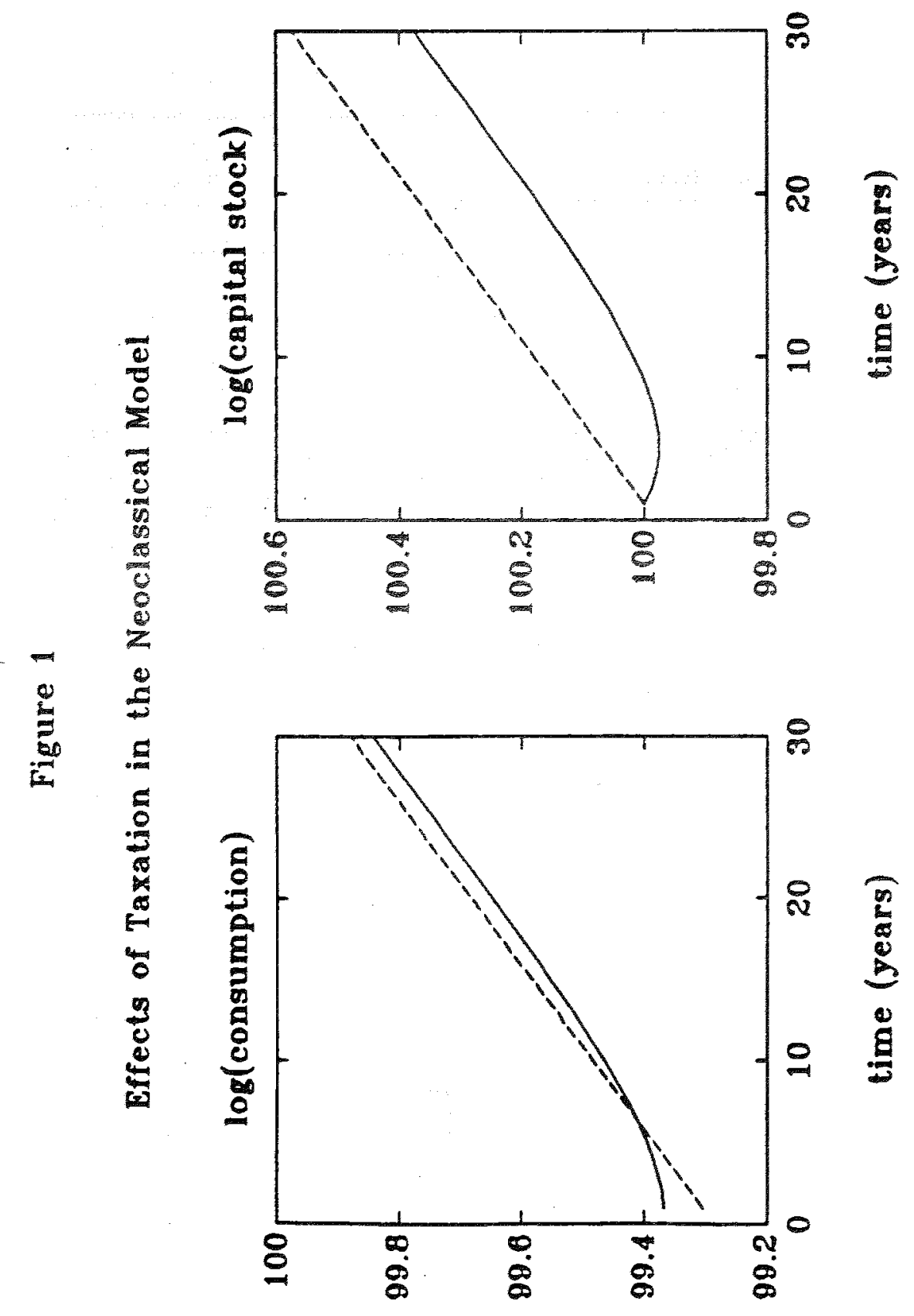




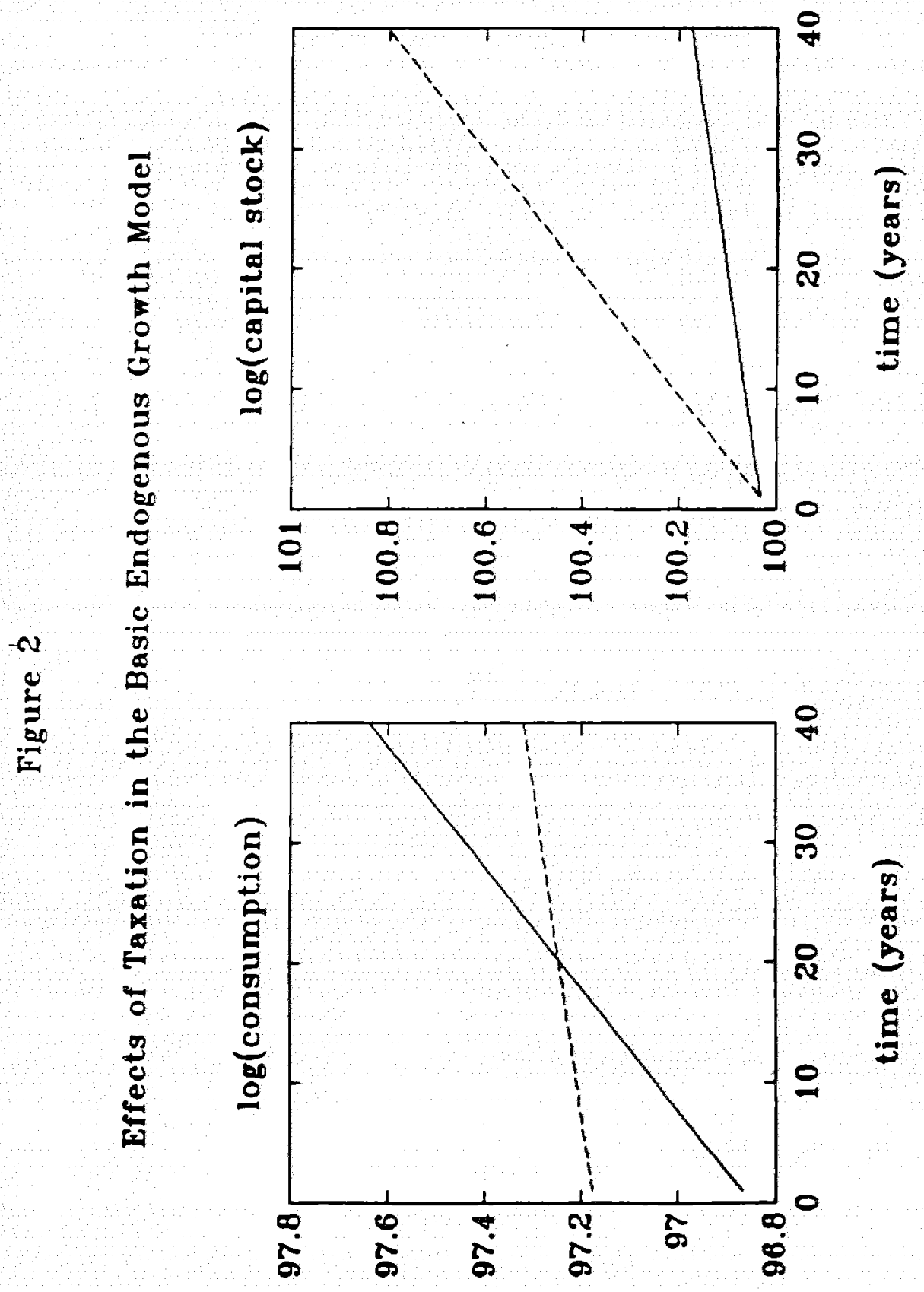




\section{Appendix \\ Calibration of Tro Sector Endogenous Grorth Hodel}

This appendir discusses the formal structure of the tro-sector endogenous gropth model outlined in the main text, as vell as our procedures for calibrating its steady state and exploring policy implications.

The representative agent in this economy solves the dynamic optimization problem

$$
\operatorname{Max} \sum_{t=0}^{\infty} \beta^{t} u\left(C_{t}\right)
$$

subject to the accumlation constraints

$$
\begin{aligned}
& R_{t+1}=\left(1-\delta_{R}\right) R_{t}+I_{R t} \\
& H_{t+1}=\theta\left(I_{H t} / H_{t}\right) H_{t}+\left(1-\delta_{H}\right) H_{t}
\end{aligned}
$$

the resource constraints

$$
\begin{aligned}
& C_{t}+I_{E t} \leq \Pi_{1} F_{1}\left(K_{1 t}, H_{1 t}\right)+T_{1 t} \\
& I_{H t} \leq \Pi_{2} F_{2}\left(R_{2 t}, M_{2 t}\right)+T_{2 t}
\end{aligned}
$$

and the factor allocation constraints

$$
\mathrm{H}_{1 \mathrm{t}}+\mathrm{M}_{2 \mathrm{t}} \leq \mathrm{HH}_{\mathrm{t}}
$$




$$
\pi_{1 t}+\pi_{2 t} \leq k_{t}
$$

To analyze equilibrium behavior, pe form the Lagrangian

$$
\begin{aligned}
\mathcal{L} & =\sum_{t=0}^{\infty} \beta^{t} u\left(C_{t}\right) \\
& +\sum_{t=0}^{\infty} \tilde{\Lambda}_{1 t}\left[\Omega_{1} F_{1 t}+T_{1 t}+\left(1-\delta_{R}\right) K_{t}-R_{t+1}-C_{t}\right] \\
& +\sum_{t=0}^{\infty} \Lambda_{2 t}\left[\Theta\left(\frac{\Omega_{2} F_{2 t}+T_{2 t}}{H_{t}}\right) H_{t}+\left(1-\delta_{H}\right) H_{t}-H_{t+1}\right] \\
& +\sum_{t=0}^{\infty} \sigma_{K t}\left[R_{t}-K_{1 t}-K_{2 t}\right] \\
& +\sum_{t=0}^{\infty} \tilde{Q}_{M t}\left[N H_{t}-M_{1 t}-M_{2 t}\right]
\end{aligned}
$$

The efficiency conditions take the folloging forms. For consumption, we have the familiar requirement that

$$
\beta^{t} D u\left(C_{t}\right)=\Lambda_{1 t}
$$

For the cross-sectoral allocations of factor stocks, we have the four conditions

$$
\bar{\Lambda}_{1 t} \Omega_{1} D_{1} F_{1}\left(R_{1 t}, H_{1 t}\right)=\bar{Q}_{k t}
$$




$$
\begin{aligned}
& \tilde{\Lambda}_{1 t} \Omega_{1} D_{2} F_{1}\left(R_{1 t}, K_{1 t}\right)=\tilde{Q}_{\mathrm{MT}} \\
& \tilde{\Lambda}_{2 t} D \theta_{t} \Omega_{2} D_{1} F_{2}\left(R_{2 t}, H_{2 t}\right)=\tilde{Q}_{K t} \\
& \tilde{\Lambda}_{2 t} D \theta_{t} \Omega_{2} D_{2} F_{2}\left(R_{2 t}, H_{2 t}\right)=\tilde{Q}_{K t}
\end{aligned}
$$

For the efficient erolution of capital stocks, we have the two shado price requirements

$$
\begin{aligned}
& \tilde{\Lambda}_{1 t}=\tilde{\Lambda}_{1, t+1}\left(1-\delta_{R}\right)+\theta_{R, t+1} \\
& \tilde{\Lambda}_{2 t}=\tilde{\Lambda}_{2, T+1}\left(1-\delta_{H}\right)+Q_{1 t, T+1}\left(t+\Lambda_{2, T+1}\left[\theta_{t+1}-D \theta_{t+1}\left(\frac{\Omega_{2} F_{2, t+1}+T_{2, t+1}}{H_{t+1}}\right)\right]\right.
\end{aligned}
$$

and the transversality conditions

$$
\begin{aligned}
& \lim _{t \rightarrow \infty} \tilde{\Lambda}_{1 t} \mathbb{R}_{t+1} \\
& \lim _{t \rightarrow \infty} \tilde{\Lambda}_{2 t} \mathbb{B}_{t+1}
\end{aligned}
$$

Finally, ve have the four resource constraints

$$
\begin{aligned}
& K_{t+1}=\Omega_{1} F_{1 t}+T_{1 t}+\left(1-\delta_{K}\right) R_{t}-C_{t} \\
& H_{t+1}=\theta\left(\frac{\Omega_{2} F_{2 t}+T_{2 t}}{H_{t}}\right) H_{t}+\left(1-\delta_{H}\right) H_{t}
\end{aligned}
$$




$$
\begin{aligned}
& R_{t}=R_{1 t}+R_{2 t} \\
& N_{t}=H_{1 t}+M_{2 t}
\end{aligned}
$$

\section{Steady State Requirements}

Consolidating the preceding conditions, ve find that the steady state is described by

$$
\begin{aligned}
& \text { (SS1) } \quad \beta\left(\gamma_{\mathrm{H}}\right)^{-\sigma}=1 /(1+r) \\
& \text { (SS2) } \quad(1+r)=\left(1-\delta_{K}\right)+\Omega_{1} D_{1} F_{1}\left(R_{1} / M_{1}, 1\right) \\
& \text { (SS3) }(1+r)=\left[\left(1-\delta_{H}\right)+W D \Theta \Omega_{2} D_{2} F_{2}+\theta-\left(F_{2} / H\right) D \Theta\right] \\
& \text { (SS4) } \quad \frac{\mathrm{D}_{1} F_{1}\left(\mathrm{R}_{1} / \mathrm{M}_{1}, 1\right)}{\mathrm{D}_{2} F_{1}\left(\mathrm{R}_{1} / \mathrm{K}_{1}, 1\right)}=\frac{\mathrm{D}_{1} F_{2}\left(\mathrm{~K}_{2} / \mathrm{K}_{2}, 1\right)}{\mathrm{D}_{2} F_{2}\left(\mathrm{~K}_{2} / \mathrm{M}_{2}, 1\right)} \\
& \text { (SS5) } \quad 1=\frac{M_{1}}{\mathrm{MH}}+\frac{\mathrm{M}_{2}}{\mathrm{MH}} \\
& \text { (SS6) } \quad \frac{\mathrm{K}}{\mathrm{NH}}=\left(\frac{\mathrm{K}_{1}}{\mathrm{M}_{1}}\right)\left(\frac{\mathrm{M}_{1}}{\mathrm{NH}}\right)+\left(\frac{\mathrm{K}_{2}}{\mathrm{H}_{2}}\right)\left(\frac{\mathrm{H}_{2}}{\mathrm{NH}}\right) \\
& \text { (SS7) } \gamma_{H}=\theta\left(I_{E} / H\right)+1-\delta_{H} \\
& \text { (SS8) } \quad I_{E} / H=F_{2}\left(\frac{K_{2}}{H_{2}} ; 1\right) \frac{K_{2}}{H}
\end{aligned}
$$


(ss9)

$$
\left(\frac{Y}{W H}\right)=E_{1}\left(R_{1} / H_{1}, 1\right)\left(\frac{H_{1}}{M H}\right)
$$

(SS10) $\quad \frac{C}{\mathrm{NH}}=\frac{Y}{\mathrm{NH}}-\left(\gamma_{\mathrm{B}}+1-\delta_{\mathrm{R}}\right) \frac{\mathrm{R}}{\mathrm{NH}}$

This system is 10 equations in the 10 unknoms $\gamma_{\mathrm{H}^{\prime}},(1+r),\left(\mathbb{R}_{1} / \mathbb{K}_{1}\right),\left(\mathbb{R}_{2} / \mathbb{H}_{2}\right)$, $\left(\mathrm{M}_{1} / \mathrm{NH}\right),(\mathrm{K} / \mathrm{HH}),\left(\mathrm{I}_{E} / \mathrm{H}\right),(\mathrm{Y} / \mathrm{NH})$ and $(\mathrm{C} / \mathrm{NH})$.

\section{Calibration}

For the purpose of determining the parameters of the steady state to match observed average growh and real interest rates, we proceed as follots. First, $z \in$ postulate CES forms for the $F_{1}$ ard $F_{2}$ turctions, so that $F_{i}$

$$
F_{i}\left(E_{i}, w_{i} ; \alpha_{i}, \alpha_{i}, \rho_{i}\right)=\mathbb{A}_{i}\left[\left(1-\alpha_{i}\right) x_{i}^{-\rho_{i}}+\alpha_{i} W_{i}^{-\rho_{i}}\right]^{-1 / \rho_{i}}
$$

Then, we compute the steady state according to the 10110uing algoritho:

Step 1: Given $A_{1}=1, \alpha_{1}$, and $\rho_{1}$, invert $(1+r)=D_{1} F_{1}\left(R_{1} / K_{1}, 1\right)+1-\delta_{R}$ to obtain steady stat $\mathrm{K}_{1} / \mathrm{K}_{1}$ ratio using (SS2).

Step 2: Given $\alpha_{1}, \alpha_{2}, \rho_{1}$ and $\rho_{2}$ calculate $\bar{x}_{2} / \mathrm{H}_{2}$ from requirement that merginal rates of transformation are equated in the tro sectors, using (SS4).

Step 3: Given the parameters of $\theta$ function-the coefficients developed in Appendix 1 (i.e., $\theta$ and $\left.A_{3}\right)$-compute $\left(I_{E} / H\right)$ consistent aith specified $\gamma_{\mathrm{H}}$ using (SS7). 
Step 4: Given the results of the preceding steps, (SS3) permitsspecification of $\Omega_{2}$-solution for the parameter $A_{2}$

$$
A_{2}=\frac{I+\delta_{H}-\left[\theta\left(I_{E} / H\right)-D \theta\left(I_{E} / H\right)\left(I_{E} / H\right)\right]}{N D \theta\left(I_{E} / H\right) \Omega_{2}\left[D_{2} F_{2}\left(X_{2} / H_{2}, 1\right) / A_{2}\right]}
$$

Step 5: Use (SS8) to compute the fraction of time in efficiency units allocated to investment in human capital, given previously determined $\left(I_{E} / H\right)$ and $\left(R_{2} / M_{2}\right)$ rith specified $N$.

$$
\left(\mathrm{H}_{2} / \mathrm{NH}\right)=\mathrm{I}_{E} /\left[\mathrm{F}_{2}\left(\frac{K_{2}}{\mathrm{H}_{2}}, 1\right)\right]
$$

Step 6: Compute $\mathrm{K}_{1} / \mathrm{HH}=1-\left(\mathrm{K}_{2} / \mathrm{NH}\right)$, using (SS5).

Step 7 : Colmpute $\frac{Y}{\mathrm{NE}}=\left(\frac{Y}{\mathrm{MI}}\right)\left(\frac{\mathbf{M}_{1}}{\mathrm{MH}}\right)=\mathrm{F}_{2}\left[\left(\frac{\mathbf{R}_{1}}{\mathbf{M}_{1}}\right), 1, A_{1}, \alpha_{1}, \rho_{1}\right] \cdot\left(\frac{\mathbf{M}_{1}}{\mathrm{NH}}\right)$, using (SS8) and the results above.

Step 8: Compute $\frac{\mathrm{K}}{\mathrm{NH}}=\left(\frac{\mathbf{K}_{1}}{\mathrm{H}_{1}} \frac{\mathbf{M}_{1}}{\mathrm{MH}}+\frac{\mathrm{K}_{2}}{\mathrm{M}_{2}} \frac{\mathbf{M}_{2}}{\mathrm{NH}}\right)$, using (SS6) and the results above.

Step $9:$ Compute $\frac{\mathrm{C}}{\mathrm{NH}}=\frac{Y}{\mathrm{NH}}-\gamma_{\mathrm{H}} \frac{\mathrm{K}}{\mathrm{NH}}+\left(1-\delta_{\mathbb{R}}\right) \frac{\mathrm{K}}{\mathrm{NH}}$, using (SS9) and the results above :

Step 10: Compute $\beta=\gamma_{\mathrm{H}}^{\sigma} /(1+r)$ using (SS1) and the results above. 